\title{
Downregulation of the $\alpha \mathrm{v} \beta 6$ Integrin via RGD Engagement Is Affinity and Time Dependent
}

\author{
DJames A. Roper, Alex L. Wilkinson, Elaine Gower, and Robert J. Slack \\ Fibrosis Discovery Performance Unit (DPU), Respiratory Therapy Area Unit (TAU), GlaxoSmithKline, Stevenage, Hertfordshire, \\ United Kingdom
}

Received October 16, 2020; accepted November 30, 2020

\section{ABSTRACT}

The arginyl-glycinyl-aspartic acid (RGD) integrin alpha-v beta-6 $(\alpha \vee \beta 6)$ has been identified as playing a key role in the activation of transforming growth factor- $\beta$ (TGF $\beta$ ) that is hypothesized to be pivotal in the development of fibrosis and other diseases. In this study, $\alpha \mathrm{v} \beta 6$ small molecule inhibitors were characterized in a range of in vitro systems to determine affinity, kinetics, and duration of TGF $\beta$ inhibition. High $\alpha \mathrm{v} \beta 6$ binding affinity was shown to be correlated with slow dissociation kinetics. Compound 1 (high $\alpha \vee \beta 6$ affinity, slow dissociation) and SC-68448 (low $\alpha \vee \beta 6$ affinity, fast dissociation) induced concentrationand time-dependent internalization of $\alpha \mathrm{v} \beta 6$ in normal human bronchial epithelial (NHBE) cells. After washout, the $\alpha \mathrm{v} \beta 6$ cell surface repopulation was faster for SC-68448 compared with compound 1. In addition, $\alpha v \beta 6$-dependent release of active TGF $\beta$ from NHBE cells was inhibited by compound 1 and SC68448. After washout of SC-68448, release of active TGF $\beta$ was restored, whereas after washout of compound 1 the inhibition of TGF $\beta$ activation was maintained and only reversible in the presence of a lysosomal inhibitor (chloroquine). However, SC68448 was able to reduce total levels of $\alpha \mathrm{v} \beta 6$ in NHBE cells if present continuously. These observations suggest $\alpha \mathrm{v} \beta 6$ can be degraded after high affinity RGD binding that sorts the integrin for lysosomal degradation after internalization, likely due to sustained engagement as a result of slow dissociation kinetics. In addition, the $\alpha \mathrm{v} \beta 6$ integrin can also be downregulated after sustained engagement of the RGD binding site with low affinity ligands that do not sort the integrin for immediate lysosomal degradation.

\section{SIGNIFICANCE STATEMENT}

The fate of RGD integrin after ligand binding has not been widely investigated. Using the $\alpha \vee \beta 6$ integrin as a case study, we have demonstrated that RGD-induced downregulation of $\alpha \vee \beta 6$ is both affinity and time dependent. High affinity ligands induced downregulation via lysosomal degradation, likely due to slow dissociation, whereas sustained low affinity ligand engagement was only able to decrease $\alpha \mathrm{v} \beta 6$ expression over longer periods of time. Our study provides a potential unique mechanism for obtaining duration of action for drugs targeting integrins.

\section{Introduction}

The integrins are a family of transmembrane glycoprotein receptors that primarily act as signaling proteins in mammals (Hynes, 1987). These heterodimeric receptors are made up of an $\alpha$ - and $\beta$-subunit, of which in mammals there are $18 \alpha$ subunits and eight $\beta$-subunit variants that are able to form up to 24 heterodimers (Hynes, 2002). The alpha-v beta- $6(\alpha \mathrm{v} \beta 6)$ integrin is a member of the arginyl-glycinyl-aspartic acid (RGD) integrin subfamily (Busk et al., 1992; Hynes, 2002) that share an amino acid binding motif [arginine $(R)$, glycine $(G)$, and aspartic acid (D)] in their endogenous ligands, with selectivity for these ligands determined by their surrounding amino acid sequences (Ruoslahti, 1996). These endogenous

This work received no external funding.

This work was previously presented at the following meeting: Gower E Wilkinson A, and Slack RJ (2017) Downregulation of the $\alpha \mathrm{v} \beta 6$ integrin can occur via short engagement with high affinity ligands or long engagement with low affinity ligands. British Pharmacological Society (BPS) Pharmacology 2017; 2017 Dec 11-13; London, UK.

https://doi.org/10.1124/jpet.120.000379.
RGD ligands include fibronectin, vitronectin, fibrinogen, von Willebrand factor, thrombospondin, laminin, tenascin, osteopontin, and the latency-associated peptide of the large latent transforming growth factor $\beta$ (TGF $\beta$ ) complex. The $\alpha \mathrm{v} \beta 6$ integrin has been shown to be upregulated in fibrotic disease (Margadant and Sonnenberg, 2010) and hypothesized to drive fibrogenesis via activation of the potent profibrotic cytokine $\operatorname{TGF} \beta$ (Munger et al., 1999). The $\alpha \mathrm{v} \beta 6$ integrin activates $\mathrm{TGF} \beta$ from the constitutively expressed latent $\mathrm{TGF} \beta$ after binding of the RGD sequence, located in the latencyassociated peptide component of the TGF $\beta$ large latent complex, to the RGD binding site located in the interface between the $\alpha \mathrm{v}$ and $\beta 6$ integrin subunits (Goodwin and Jenkins, 2009). This interaction results in the $\beta 6$ cytoplasmic domain binding to intracellular actin cytoskeleton that, when activated by mechanical stretch, induces a conformational change in the large latent complex and presentation of active $\mathrm{TGF} \beta$ to its receptors, evoking canonical $\mathrm{TGF} \beta$ signaling (Munger et al., 1999; Xu et al., 2009; Tatler and Jenkins, 2012).

ABBREVIATIONS: BEBM, bronchial epithelial basal medium; GAPDH, glyceraldehyde-3-phosphate dehydrogenase; HCS, high content screening; NHBE, normal human bronchial epithelial; PAl-1, plasminogen activator inhibitor-1; PE, phycoerythrin; RGD, arginyl-glycinyl-aspartic acid; TGF $\beta$, transforming growth factor- $\beta$; $t_{1 / 2}$, half-life; TMLC, transformed mink lung cell; $\alpha \mathrm{v} \beta 6$, alpha-v beta-6. 

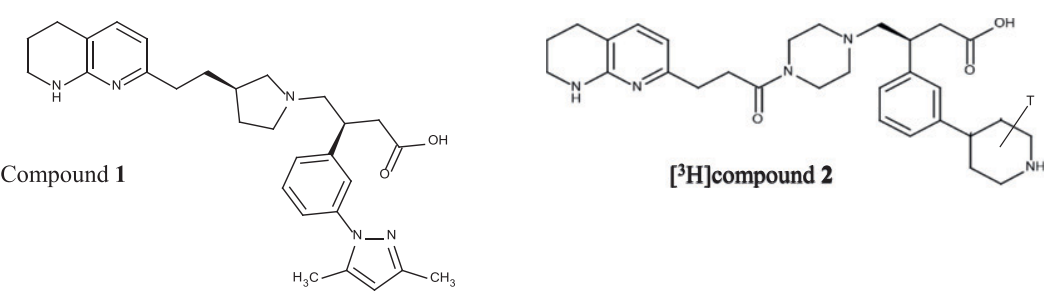

$\left[{ }^{3} \mathrm{H}\right]$ compound 2

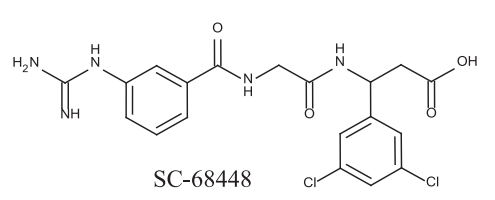

Fig. 1. The chemical structures of the small molecules used in this study.<smiles>Cc1cccc(-c2[nH]c(C(C)(C)C)nc2-c2ccc3nccnc3c2)n1</smiles>

Due to its potential as a therapeutic target in fibrosis, several $\alpha \mathrm{v} \beta 6$ drug discovery initiatives have been ongoing for the last decade. The furthest advanced of these is a selective non-RGD $\alpha \mathrm{v} \beta 6$ monoclonal antibody, BG00011 (Horan et al., 2008), that was until recently in a phase II idiopathic pulmonary fibrosis clinical study (NCT03573505). In addition, over recent years there has been a drive within the pharmaceutical industry to develop small molecule RGD-mimetics via both the inhaled (Maden et al., 2018) and oral routes (Hatley et al., 2018), targeting fibrotic disease and cancers within the lung and beyond.

As is the case for majority of the $\alpha \mathrm{v}$ integrins, the relationships between $\alpha \mathrm{v} \beta 6$ RGD binding site affinity, receptor kinetics, and downregulation have not been fully explored. Although the internalization of the $\alpha \mathrm{v} \beta 6$ integrin has been well established after binding of ligands to the RGD binding site (Ramsay et al., 2007; Slack et al., 2016), less is known of the fate of the integrin in relation to the RGD binding site occupancy over time. The determination of these relationships is important to understand when designing drug candidates targeting $\alpha \mathrm{v} \beta 6$ in the clinic, as they can influence the duration of pharmacodynamic effect. Consequently, this will influence the dose required for efficacy and dosing frequency, which will factor into the likelihood of maintaining a therapeutic window over toxicological effects.

The aim of this present study is to investigate the role of $\alpha \mathrm{v} \beta 6$ integrin binding affinity and dissociation kinetics on the internalization and recycling kinetics of the integrin using two small molecule RGD-mimetics with different pharmacological profiles. In addition, the total cellular levels of $\alpha \mathrm{v} \beta 6$ were tracked after internalization to enable the impact of duration of RGD binding site engagement on $\alpha \mathrm{v} \beta 6$ expression, and therefore subsequent activation of $\mathrm{TGF} \beta$, to be determined.

\section{Materials and Methods}

Materials. Compound 1 (Anderson et al., 2016), compound 2 (Rowedder et al., 2017), SC-68448 (Carron et al., 1998), and SB525334 (Grygielko et al., 2005) (Fig. 1) were synthesized by the Fibrosis Discovery Performance Unit Medicinal Chemistry group at GlaxoSmithKline Medicines Research Centre (Stevenage, UK). Compound 2 was radiolabeled with $\left[{ }^{3} \mathrm{H}\right]$ by RC TRITEC Ltd. (Teufen, Switzerland) and had a specific activity of $16.1 \mathrm{Ci} / \mathrm{mmol}$. All other chemicals and reagents were purchased from Sigma-Aldrich Co. Ltd. (Gillingham, UK) unless otherwise stated. Normal human bronchial epithelial (NHBE) cells, growth medium, and supplements were purchased from Lonza (Lonza Group Ltd., Basel, Switzerland) and maintained in culture as previously described (Slack et al., 2016). The epithelial transformed mink lung cell (TMLC) line (Abe et al., 1994) was obtained from Daniel Rifkin (New York University, NY) and maintained in culture as previously described (Weinreb et al., 2004). All other cell culture media and reagents were obtained from Invitrogen (Invitrogen Ltd., Paisley, UK). All tissue culture flasks and plates were purchased from Greiner Bio-One (Firckenhausen, Germany) unless otherwise stated. All antibodies used were commercially available and obtained from R\&D Systems (Minneapolis, MN) unless otherwise stated and at a stock concentration of $10 \mu \mathrm{g} / \mathrm{ml}$. These included, for flow cytometry, phycoerythrin (PE)-conjugated mouse IgG2B isotype control (IgG2B-PE) (product \# IC0041P) and PEconjugated mouse monoclonal non-function blocking, anti-human integrin beta- 6 (product \# FAB4155P) and, for high content screening (HCS), mouse monoclonal anti-human integrin beta-6 (product \# MAB4155) and Alexa Fluor 488 goat IgG anti-mouse Invitrogen (product \# A-11001; Invitrogen Ltd.). Cellular assays and radioligand binding assays were completed with a final DMSO concentration of $0.1 \%$ and $1 \%$, respectively. Purified soluble protein for the human $\alpha \mathrm{v} \beta 6$ integrin (product \# 3817-AV) was purchased from R\&D Systems Inc.

Radioligand Binding Studies. All radioligand binding experiments were performed via filtration binding in 96-well deep plates at $37^{\circ} \mathrm{C}$ as previously described (Rowedder et al., 2017). For determining the affinity of small molecules at the $\alpha \mathrm{v} \beta 6$ integrin, competition binding studies were completed by incubating integrin protein $(0.3$ $\mathrm{nM})$ with a fixed concentration of $\left[{ }^{3} \mathrm{H}\right]$ compound $2\left(\sim K_{\mathrm{D}}\right)$ and increasing concentrations of unlabeled test ligand for 6 hours prior to filtration. To determine the receptor dissociation rates of unlabeled integrin ligands, $2 \times K_{\text {I }}$ concentrations of unlabeled small molecule RGD-mimetics were incubated with $\alpha \mathrm{v} \beta 6$ protein for 1 hour prior to addition of excess $\left[{ }^{3} \mathrm{H}\right]$ compound $2\left(50 \times K_{\mathrm{D}}=\sim 50 \mathrm{nM}\right)$ and then incubated at $37^{\circ} \mathrm{C}$ for varying times up to 48 hours prior to filtration.

Ligand-Induced $\alpha v \beta 6$ Internalization and Recycling in NHBE Cells. The measurement of surface and intracellular $\alpha \mathrm{v} \beta 6$ in NHBE cells was determined via flow cytometry using methods previously described (Slack et al., 2016). For HCS studies, supplement-starved NHBE cells in bronchial epithelial basal medium (BEBM) were plated in collagen I-coated 96-well imaging plates $(20,000$ cells/well) and treated with vehicle or test compound for up to 48 hours prior to $\beta 6$ integrin staining with mouse anti-human integrin $\beta 6$, then goat anti-mouse IgG Alexa Fluor 488 antibody (Invitrogen Ltd., Renfrewshire, UK). Image acquisition and analysis of stained cells were performed using the Arrayscan VTI High Content Reader (Thermo Fisher Scientific, MA), applying bioapplications to quantify $\beta 6$ immunofluorescence. Nuclear staining was completed with 
Hoechst 33342 dye (Invitrogen Ltd.) to measure cell numbers, and if required cells were permeabilized with $0.2 \% \mathrm{w} / \mathrm{v}$ saponin (flow cytometry) or Triton X-100 (HCS) to determine total $\alpha \mathrm{v} \beta 6$ staining (membrane and intracellular).

Measurement of TGF $\beta$ Activation and Signaling. For the measurement of concentration-dependent effects of test compounds on TGF $\beta$ signaling, supplement-starved NHBE cells in BEBM $(20,000$ cells/well) were plated in collagen I-coated 96 -well plates and treated with vehicle $(0.1 \%$ DMSO) or test compound for 24 hours. Cells were lysed in ice-cold cell lysis buffer [included in Milliplex TGF $\beta$ Signaling Magnetic Bead Panel 6 plex (Merck Millipore, Billerica, MA) supplemented with Halt Protease and Phosphatase Inhibitor Cocktail $(100 \times)$; Life Technologies Ltd., Paisley, UK], then phospho mothers against decapentaplegic homolog 2 (pSmad2 )measured and normalized to glyceraldehyde-3-phosphate dehydrogenase (GAPDH). The Milliplex TGF $\beta$ Signaling Magnetic Bead Panel 6 plex (Merck Millipore) Luminex assay was used to quantify pSmad2 and GAPDH, according to the manufacturer's instructions.

Activation of TGF $\beta$ via $\alpha \mathrm{v} \beta 6$ in NHBE cells was determined in a TMLC co-culture system as previously described (Xu et al., 2009). Briefly, supplement-starved NHBE cells in BEBM were plated in collagen I-coated 96 -well plates (25,000 cells/well) and left to adhere for 24 hours prior to addition of TMLCs containing $20 \mu \mathrm{M}$ lysophosphatidic acid (25,000 cells/well). Vehicle $(0.1 \%$ DMSO) or test compound was added and incubated for 24 hours in the absence or presence of chloroquine prior to addition of cell lysis and detection reagents (Promega Corporation, Madison, WI). Plates were then incubated at ambient temperature $\left(20-22^{\circ} \mathrm{C}\right)$ for 5 minutes before supernatants were transferred to a 96 -well, white, solid bottom plates and luminescence read on a MicroBeta TriLux (PerkinElmer LAS UK Ltd., Beaconsfield, UK). For washout studies, vehicle or test compound in the absence or presence of $10 \mu \mathrm{M}$ chloroquine was incubated with the NHBE cell/TMLC co-culture for 1 hour prior to washout. TGF $\beta$ was quantified by comparing values obtained under experimental conditions to readings obtained from a standard curve derived from increasing concentrations of active TGF $\beta$ added to the co-culture under identical conditions.

Quantification of $\beta 6$ and Plasminogen Activator Inhibitor-1 mRNA Expression in NHBE Cells. Cultured NHBE cells were seeded on to collagen I-coated 24 -well plates $(50,000$ cells/well) and treated with vehicle $(0.1 \%$ DMSO) or test compound for 24 hours. Cells were then washed with ice-cold PBS and stored at $-80^{\circ} \mathrm{C}$. Total RNA was isolated using the RNeasy mini kit (Qiagen, West Sussex, UK) with on-column DNase digestion as per the manufacturer's instructions. Total RNA was reverse transcribed using the high-capacity complementary DNA reverse transcription kit (Life Technologies Ltd., Paisley, UK) as per the manufacturer's instructions. Integrin $\beta 6$, plasminogen activator inhibitor-1 (PAI-1), and GAPDH (housekeeping gene) gene expression were determined using the respective TaqMan real-time polymerase chain reaction primers ITGB6 (Hs00168458_m1), PAI-1 (Hs01126604_m1), and GAPDH (Hs99999905_m1) (Life Technologies Ltd., Paisley, UK) on a LightCycler 480 (Roche, Basil, Switzerland). This was completed using a LightCycler 480 Probes Master kit as per the manufacturer's instructions with a preincubation at $95^{\circ} \mathrm{C}$ for 10 minutes, amplification at $95^{\circ} \mathrm{C}$ for 10 seconds followed by $60^{\circ} \mathrm{C}$ for 30 seconds (repeated for 45 cycles), and cooling at $4^{\circ} \mathrm{C}$ for 30 seconds. $2^{-\Delta \Delta C t}$ (fold increase in gene expression relative to comparator [control $(0.3 \%$ DMSO) at $t=0$ hours)] for integrin $\beta 6$ and PAI-1 were calculated as described previously (Livak and Schmittgen, 2001) with gene expression normalized to the housekeeping gene (GAPDH).

Data Analysis. Statistical analyses were completed using Prism 8.0 (GraphPad Software, San Diego, CA). Statistical significance between two data sets was tested using a Student's unpaired $t$ test. One-way ANOVA was used for comparison of more than two data sets and, when significance was observed, an appropriate post-test completed. For determining a statistical correlation between two data sets, a Pearson correlation was completed. Radioligand binding data were normalized to total (1\% DMSO) and nonspecific binding $(10 \mu \mathrm{M}$
A

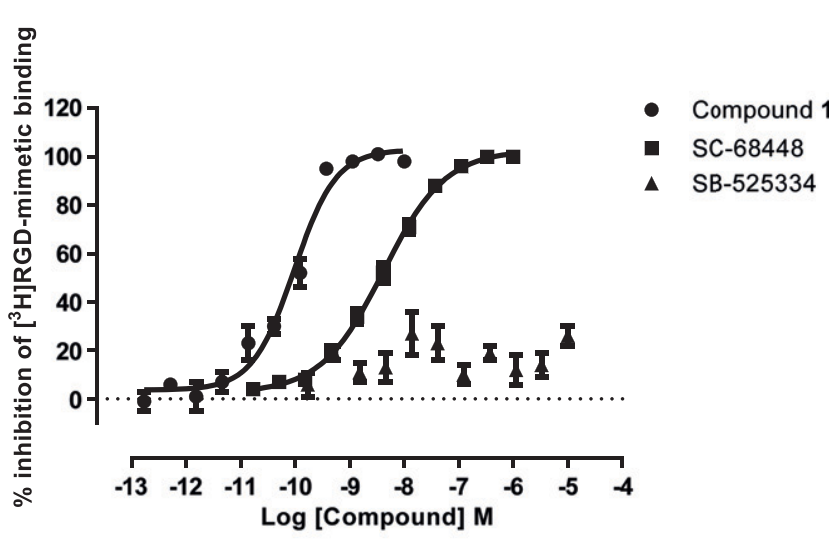

B

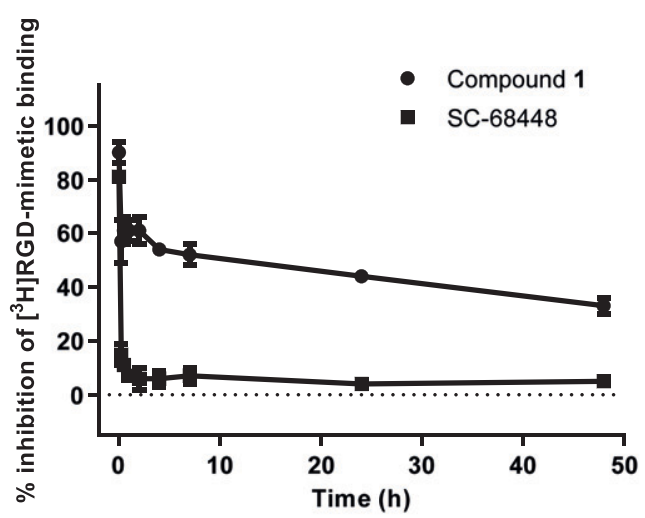

C

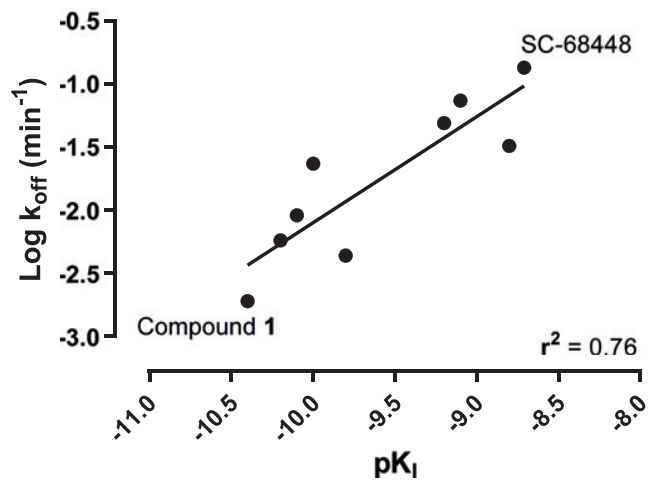

Fig. 2. Competition and dissociation binding profiles for small molecule molecules and the $\alpha \mathrm{v} \beta 6$ integrin. (A) Competition binding curves for compound 1, SC-68448, and SB-525334 against the $\alpha \mathrm{v} \beta 6$ integrin. (B) The dissociation profile of compound 1 and SC-68448 from the $\alpha \mathrm{v} \beta 6$ integrin. (C) Correlation of $\log k_{\text {off }}$ vs. negative $\log _{10}$ of $K_{\mathrm{I}}\left(p K_{\mathrm{I}}\right)$ for a set of $\alpha \mathrm{v} \beta 6$ RGD-mimetics with a range of affinities. Total and nonspecific binding values were measured at each time point in the presence of vehicle (1\% DMSO) and $10 \mu \mathrm{M}$ SC-68448, respectively, and were used to calculate the percent inhibition of radioligand bound to the $\alpha \mathrm{v} \beta 6$ integrin. Data shown are means \pm S.E.M. (A and $\mathrm{B}$ ) of at least four individual experiments carried out in singlicate or quadruplicate.

SC-68448). HCS internalization, TGF $\beta$ signaling, and TGF $\beta$ activation data were normalized to vehicle control (0.1\% DMSO) and a control $\alpha \mathrm{v} \beta 6$ inhibitor $(1 \mu \mathrm{M})$. Flow cytometry internalization data were normalized to human $\beta 6$-PE staining in the absence of compound and background IgG2B-PE staining. Unless otherwise indicated, data shown graphically and in the text are either means \pm S.D. or, where three or more data points/individual experiments have been completed, means \pm S.E.M. 


\section{Results}

Affinity and Dissociation Kinetics of $\alpha v \beta 6$ Inhibitors. To determine the affinity of unlabeled integrin ligands at the $\alpha \mathrm{v} \beta 6$ integrin, competition displacement binding curves were measured against $\left[{ }^{3} \mathrm{H}\right]$ compound $\mathbf{2}$. Compound $\mathbf{1}$ was shown to bind with high $\mathrm{pM}$ affinity to the $\alpha \mathrm{v} \beta 6$ integrin, whereas SC-68448 demonstrated an approximate 70-fold lower affinity (Fig. 2A; Table 1). The transforming growth factor beta receptor I (TGF $\beta$ RI) inhibitor SB-525334 was shown not to bind to the $\alpha \mathrm{v} \beta 6$ integrin at concentrations up to $10 \mu \mathrm{M}$. To allow the ranking of unlabeled ligands in terms of rate of dissociation from the $\alpha \mathrm{v} \beta 6$ integrin, the association of $\left[{ }^{3} \mathrm{H}\right]$ compound 2 was used as surrogate for the dissociation of an unlabeled ligand from a preformed unlabeled ligand/integrin complex. Using this method, the dissociation profiles for compound 1 and SC-68448 were generated, with compound $\mathbf{1}$ demonstrating slow- and SC68448 fast- $\alpha \mathrm{v} \beta 6$ dissociation kinetics (Fig. 2B; Table 1). The dissociation constant $\left(k_{\text {off }}\right)$ was calculated for compound $\mathbf{1}$, SC-68448, and a set of $\alpha \mathrm{v} \beta 6$ integrin ligands to allow correlation with affinity (Fig. 2C; Table 1). A significant correlation (Pearson correlation, $P<0.01$ ) was observed between affinity and $k_{\text {off }}$, with a high affinity engagement of the $\alpha \mathrm{v} \beta 6$ integrin resulting in a slow dissociation rate. From the set of molecules tested, compound 1 demonstrated the highest affinity and slowest off-rate, whereas SC-68448 was shown to have the lowest affinity and fastest off-rate.

Ligand-Induced $\alpha v \beta 6$ Internalization and Kinetics. In high content cell imaging studies using NHBE cells, compound 1 and SC-68448 caused concentration-dependent $\alpha \mathrm{v} \beta 6$ internalization of surface integrins after a 24-hour incubation, with no effect on cell count (Fig. 3, A and B). To determine the rates of ligand-induced internalization, in flow cytometric studies the surface expression of $\alpha \mathrm{v} \beta 6$ was measured over time after the addition of a maximal concentration of test ligand, as determined in concentration-response curve studies. Both compound 1 and SC-68448 caused a rapid internalization of $\alpha \mathrm{v} \beta 6$ with comparable maximal loss of cell surface integrin observed over the 1-hour time course studied (Fig. 3C). The maximal effect observed was less than $100 \%$ compared with the HCS assay that was likely a result of the normalization to the isotype control in the flow cytometry system. The return of $\alpha \mathrm{v} \beta 6$ to the surface membrane after washout was $\sim 3$-fold slower for the compound 1 compared with SC-68448 (Fig. 3C; Table 1).

Concentration- and Time-Dependent Inhibition of TGF $\beta$ Activation and Signaling. To demonstrate the inhibition of $\alpha \mathrm{v} \beta 6$-mediated TGF $\beta$ activation by compound $\mathbf{1}$ and SC-68448, Smad2 phosphorylation was measured in NHBE cells. Compound 1 and SC-68448 inhibited Smad2 phosphorylation in a concentration-dependent manner, as did the TGF $\beta$ RI inhibitor SB-525334 (Fig. 4A; Table 1). To confirm if the differences in $\alpha \mathrm{v} \beta 6$ return half-life $\left(t_{1 / 2}\right)$ observed between compound 1 and SC-68448 resulted in a similar effect on TGF $\beta$ activation, washout studies were completed measuring TGF $\beta$ release from NHBE cells. After washout, the inhibitory effect of SC-68448 was completely lost, whereas compound 1 maintained an approximate 70\% inhibition of $\mathrm{TGF} \beta$ release (Fig. $4 \mathrm{~B}$ ). To determine the mechanism by which compound 1 caused the prolonged postwashout inhibition of $\alpha \mathrm{v} \beta 6$-mediated TGF $\beta$ release from NHBE cells, studies were also completed in the absence and presence of the lysosomal degradation inhibitor chloroquine. In the presence of chloroquine 


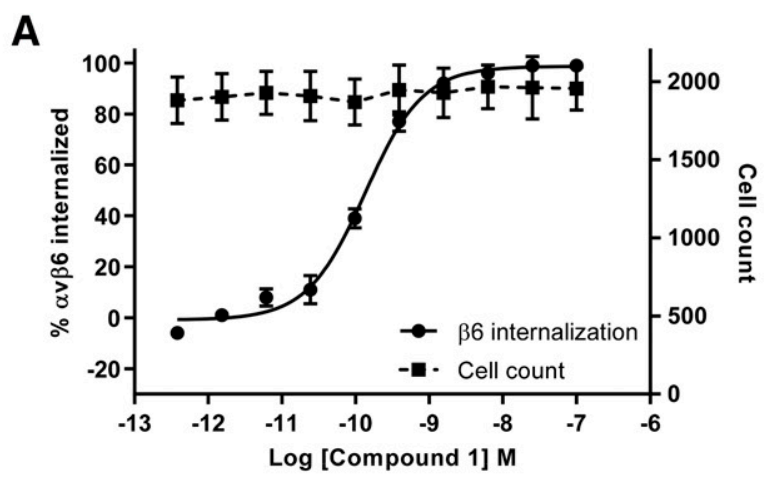

[Compound 1]
Fig. 3. RGD small molecule-induced internalization and surface repopulation kinetics of the $\alpha \mathrm{v} \beta 6$ integrin. (A) Internalization concentration response curve for the $\alpha \mathrm{v} \beta 6$ integrin in NHBE cells induced by compound $\mathbf{1}$ (cell count shown for comparison) determined by high content screening. Panel below shows example images of NHBE cell $\beta 6$ immunofluorescence (green stain) and the effect of increasing concentrations of compound $\mathbf{1}$. Nuclear staining with Hoechst 33342 dye is also shown (blue stain). (B) Internalization concentration response curve for the $\alpha \mathrm{v} \beta 6$ integrin in NHBE cells induced by SC-68448 (cell count shown for comparison) determined by high content screening. (C) Internalization kinetics of the $\alpha \mathrm{v} \beta 6$ integrin posttreatment with compound 1 and SC-68448 followed by return of $\alpha \mathrm{v} \beta 6$ to cell surface after compound washout (1 hour after addition) determined by flow cytometry. Cell count (A and B) was determined by nuclear staining with Hoechst 33342 dye. Data shown are means \pm S.E.M. of four individual experiments carried out in duplicate.

C

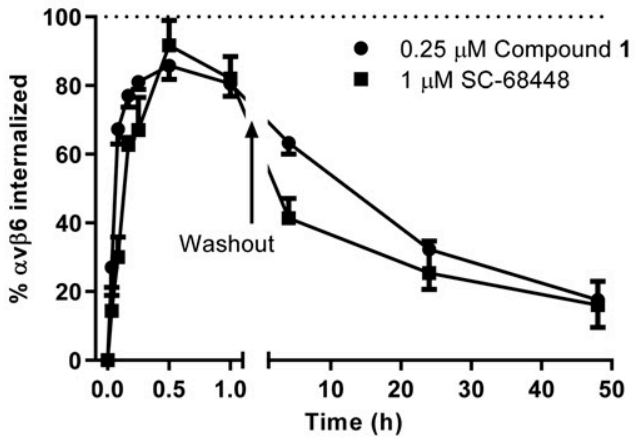

there was no statistical difference for levels of TGF $\beta$ activation inhibited by SC- 68448 after washout compared with washout conditions in the absence of chloroquine (ANOVA, Bonferroni post-test, $P>0.05$ ). This was not the case for compound $\mathbf{1}$, where the partial reversal of inhibition caused by washout in the absence of chloroquine was significantly further reversed in the presence of chloroquine (ANOVA, Bonferroni post-test, $P<0.01$ ) (Fig. 4B).

Time-Dependent Downregulation of Total Cell $\boldsymbol{\alpha} \mathbf{v} \boldsymbol{\beta} 6$. To investigate the time course of downregulation of the $\alpha \mathrm{v} \beta 6$ integrin after continuous RGD binding site engagement, and for comparison with direct TGF $\beta$ RI inhibition, the total expression in NHBE cells was monitored over time in the presence of a maximum concentration of compound $\mathbf{1}, \mathrm{SC}-68448$, and SB-525334. Compound 1 and SC-68448 both caused downregulation of $\alpha \mathrm{v} \beta 6$ in a biphasic manner with an early phase over the first 8 hours and a late phase from 8 to 48 hours. Overall total $\alpha \mathrm{v} \beta 6$ expression was reduced to a greater extent by compound 1 compared with SC-68448 with significantly lower levels observed at 48 hours (ANOVA, Bonferroni post-test, $P<0.01$ ) (Fig. 5A). SB-525334 only reduced $\alpha \mathrm{v} \beta 6$ expression at the 48 hour time point.

To further demonstrate the inhibition of $\alpha \mathrm{v} \beta 6$-mediated $\operatorname{TGF} \beta$ activation and determine effects on the level of $\beta 6$ integrin subunit in NHBE cells after compound addition, mRNA expression of PAI-1 (profibrotic mediator downstream of TGF $\beta$ RI/II pathway activation) and the $\beta 6$ integrin subunit were investigated. Both the activin receptor-like kinase 5 (ALK5 or TGF $\beta$ RI) inhibitor SB-525334 and compound 1 caused a significant downregulation of $\beta 6$ and PAI-1 mRNA (ANOVA, Dunnett post-test, with $P<0.01$ for $\beta 6$ and $P<0.05$ 
for PAI-1) over a 24-hour incubation period compared with control (0.3\% DMSO) (Fig. 5B).

\section{Discussion}

Although routinely completed for other transmembrane receptors, such as G protein-coupled receptors, the relationship between receptor binding kinetics and affinity has not been extensively studied in the context of integrins. Therefore, the initial aim of this study was to investigate the RGD binding site affinity and dissociation kinetics of a range of small molecule $\alpha \mathrm{v} \beta 6$ integrin RGD-mimetics. As it has been widely demonstrated that the binding of RGD ligands to $\alpha \mathrm{v} \beta 6$ induces internalization of the integrin (Hausner et al., 2009; Saha et al., 2010), it was also deemed of interest to examine the effect of small molecule RGD-mimetics with different affinity and receptor kinetics on the internalization and recycling kinetics of $\alpha \mathrm{v} \beta 6$. As a natural follow-on from this, the subsequent effect on the total cellular levels of $\alpha \mathrm{v} \beta 6$ were investigated after internalization. This would enable the impact of the duration of RGD binding site engagement on $\alpha \mathrm{v} \beta 6$ expression to be determined, as well as the functional consequences by measuring the activation of TGF $\beta$.

The dissociation rates for a set of $\alpha \mathrm{v} \beta 6$ RGD ligands, with affinities across a 100-fold range, were measured, and an increase in affinity for the receptor was observed to be correlated with a slower $k_{\text {off }}$ Generally, at steady state, the affinity $\left(K_{\mathrm{D}}\right)$ of a ligand and its protein/receptor binding partner is defined by the ratio of the $k_{\text {off }}$ and association constant $\left(k_{\text {on }}\right)$ and is a measure of the likelihood of the ligandreceptor complex to dissociate (Hulme and Trevethick, 2010). Therefore, a high affinity ligand would be predicted to have a lower $k_{\text {off }}$ value and a slower dissociation from the protein/ receptor. This was shown to be the case for the RGD binding interaction at the $\alpha \mathrm{v} \beta 6$ integrin. Using the highest (compound 1) and lowest (SC-68448) affinity $\alpha \mathrm{v} \beta 6$ tool small molecules, the internalization of the $\alpha \mathrm{v} \beta 6$ integrin was investigated. The potency observed for induction of internalization by compound 1 and SC-68448 tracked well with their $\alpha \mathrm{v} \beta 6$ affinity with a comparable difference between $\mathrm{EC}_{50}$ and $K_{\mathrm{D}}$ values of $\sim 100$ fold, as was the case for the $\mathrm{IC}_{50}$ values for functional inhibition of TGF $\beta$ production (i.e., pSmad 2 levels as measure of the TGF $\beta$ canonical pathway). Both molecules were observed to internalize $\alpha \mathrm{v} \beta 6$ very quickly and with comparable $t_{1 / 2}$ values that were measured within minutes of addition. The more interesting observations in this study were the rates of recycling or return of $\alpha \mathrm{v} \beta 6$ to the cell surface after washout of ligand. After washout of compound 1, $\alpha \mathrm{v} \beta 6$ returned to the cell surface $\sim 3$-fold slower compared with SC-68448.

The rate of return of $\alpha \mathrm{v} \beta 6$ to the cell surface observed in these studies after washout of compound 1 compared with that of endogenous turnover of $\alpha \mathrm{v} \beta 6$ is considerably slower (Ramsay et al., 2007; Wang et al., 2011), suggesting that the internalized ligand $-\alpha \mathrm{v} \beta 6$ complex is potentially degraded and that returning $\alpha \mathrm{v} \beta 6$ is newly synthesized. To further develop this hypothesis, the lysosomal inhibitor chloroquine was tested in a system measuring the activation of TGF $\beta$ to observe its effect on compound 1. Chloroquine in its unprotonated form can freely diffuse across cell and organelle membranes; however, it becomes trapped in lysosomes once protonated due to the low $\mathrm{pH}$ of this environment (Solomon and Lee, 2009). In this form it has been shown to inhibit proteolytic
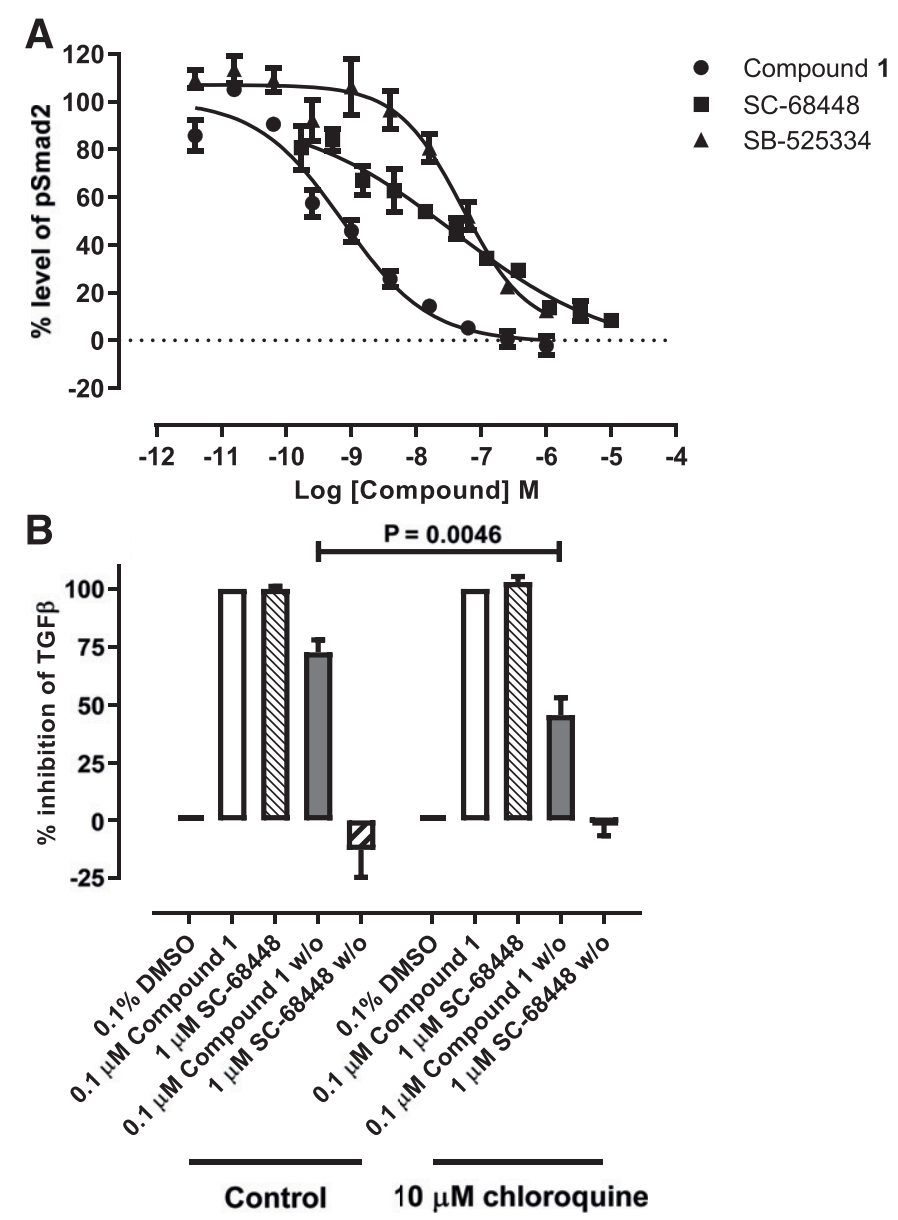

Fig. 4. Concentration- and time-dependent inhibition of $\alpha \mathrm{v} \beta 6$-mediated $\operatorname{TGF} \beta$ activation. (A) Concentration-dependent inhibition of pSmad 2 levels in NHBE cells by compound 1, SC-68448, and SB-525334 (TGF $\beta$ RI inhibitor). (B) Duration of action of the inhibition of compound 1 on TGF $\beta$ activation, and the effect of the lysosomal degradation inhibitor chloroquine, measured in an NHBE cell and TMLC (expressing the firefly luciferase under the control of a TGF $\beta$-sensitive portion of the PAI-1 promoter) co-culture system (ANOVA, Bonferroni post-test). Data shown are means \pm S.E.M. of at least four individual experiments carried out in duplicate or quadruplicate.

processes and therefore has been used as a tool for determining mechanisms of receptor turnover (Dunmore et al., 2013). In washout experiments using NHBE cells investigating $\alpha \mathrm{v} \beta 6$ mediated inhibition of TGF $\beta$ activation, the sustained duration of inhibition observed with compound 1 was reversed in the presence of chloroquine. This observation suggests that after internalization of $\alpha \mathrm{v} \beta 6$ by compound $\mathbf{1}$, the integrin is sorted for degradation in lysosomes. Interestingly, for the low affinity $\alpha \mathrm{v} \beta 6$ ligand SC-68448 with a fast dissociation profile, the sustained duration of inhibition of TGF $\beta$ activation is not observed. Therefore, compound $\mathbf{1}$ causes a more prolonged downregulation of $\alpha \mathrm{v} \beta 6$ in this system compared with the lower affinity ligand SC-68448.

The high affinity of compound $\mathbf{1}$ for the $\alpha \mathrm{v} \beta 6$ integrin combined with its slow dissociation profile likely results in a prolonged activation of the integrin in intracellular vesicles. It could be hypothesized that the longer the integrin is engaged at the RGD site after internalization, as a result of slow dissociation kinetics, the more likely it is to be intracellularly designated for degradation, as has been observed 
A

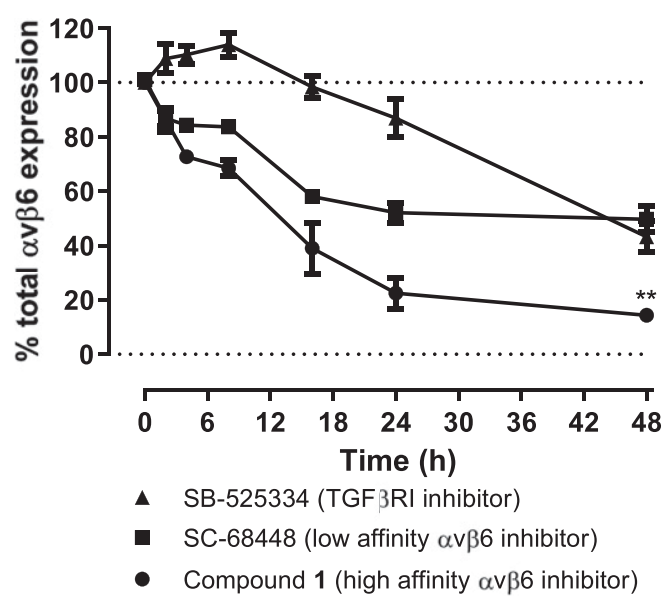

B

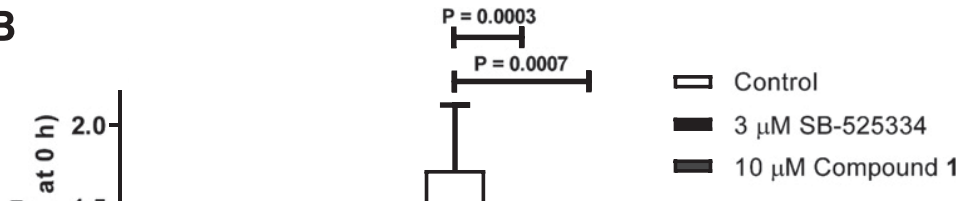

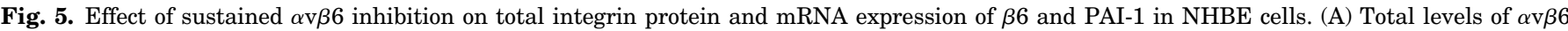

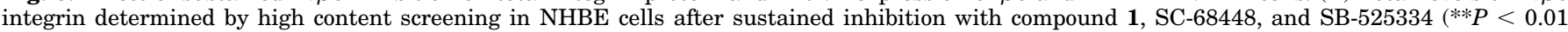

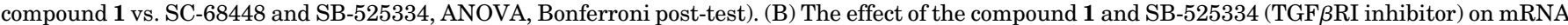

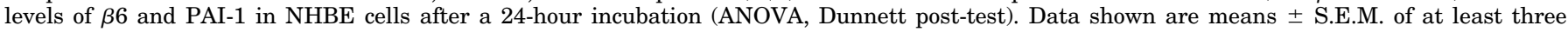
individual experiments carried out in duplicate or quadruplicate.

with other small molecule/protein interactions (Long et al., 2012; Harling et al., 2013). The prolonged activation of the RGD integrin $\alpha 5 \beta 1$ has been shown to delay its recycling back to the cell surface of A2780 cells after internalization, as a result of sorting into lysosomes prior to transportation back to the plasma membrane (Dozynkiewicz et al., 2012). A similar mechanism is hypothesized here for degradation of $\alpha \mathrm{v} \beta 6$, where compound $\mathbf{1}$ binds with high affinity, activates and internalizes the integrin, and remains bound intracellularly, causing sustained activation and sorting of the integrin for lysosomal degradation rather than recycling. This then ultimately results in prolonged duration of inhibition of $\alpha \mathrm{v} \beta 6$ mediated TGF $\beta$ activation.

Many transmembrane based receptors self-regulate their expression on cell surfaces by downregulating upon continuous activation after sustained orthosteric binding of ligands (Kelly et al., 2008) as a homeostatic control of their signaling pathways. To assess if this was also the case for the $\alpha \mathrm{v} \beta 6$ integrin, total expression was tracked after continuous engagement over 48 hours with a maximal concentration of either compound 1 or SC-68448. Both molecules resulted in the reduction in the total amount of integrin but interestingly to different degrees, with compound $\mathbf{1}$ inducing significantly lower expression. This demonstrated that although low affinity engagement of the RGD site by SC-68448 for short periods of time did not induce downregulation, prolonged binding, activation, and internalization resulted in total expression levels being reduced. The difference between the effect observed with compound 1 and SC-68448 suggests that the high affinity/slow dissociation-induced downregulation combined with the continuous engagement is additive with respect to the effect on $\alpha \mathrm{v} \beta 6$ expression. In addition, blockade of the TGF $\beta$ pathway with SB-525334 also caused downregulation of $\alpha \mathrm{v} \beta 6$ but over a much longer timeframe. This demonstrated that the integrin is under transcriptional control by TGF $\beta$ in this system, as has been shown previously (Zambruno et al., 1995; Wang et al., 1996), and was confirmed by effects on $\beta 6$ gene expression.
In conclusion, this study has demonstrated that high affinity binding to $\alpha \mathrm{v} \beta 6$ is driven by slow dissociation from the integrin. High affinity RGD ligand binding at the $\alpha \mathrm{v} \beta 6$ integrin induces downregulation, as a result of lysosomal degradation after integrin internalization, likely due to sustained engagement as a result of the slow dissociation kinetics. This novel relationship has not been demonstrated before and offers a unique mechanism for achieving sustained target engagement that can be driven by drug $C_{\text {max }}$ rather than slow clearance. In addition, a further novel finding from this study is that $\alpha \mathrm{v} \beta 6$ can be downregulated after continuous engagement of the RGD binding site with low affinity ligands, potentially as a homeostatic mechanism for controlling integrin activation.

\section{Acknowledgments}

The authors would like to acknowledge the Fibrosis Discovery Performance Unit (DPU) Medicinal Chemistry team at GlaxoSmithKline for the synthesis of compound 1, compound 2, SC-68448, and SB525334. All studies were funded by GlaxoSmithKline.

\section{Authorship Contributions}

Participated in research design: Roper, Wilkinson, Gower, Slack. Conducted experiments: Roper, Wilkinson, Gower, Slack.

Performed data analysis: Roper, Wilkinson, Gower, Slack.

Wrote or contributed to the writing of the manuscript: Roper, Slack.

\section{References}

Abe M, Harpel JG, Metz CN, Nunes I, Loskutoff DJ, and Rifkin DB (1994) An assay for transforming growth factor-beta using cells transfected with a plasminogen activator inhibitor-1 promoter-luciferase construct. Anal Biochem 216:276-284.

Anderson NA, Campbell IB, Fallon BJ, Lynn SM, Macdonald SJ, Pritchard JM, Procopiou PA, Sollis SL, and Thorp LR (2016) Synthesis and determination of absolute configuration of a non-peptidic $\alpha \mathrm{v} \beta 6$ integrin antagonist for the treatment of idiopathic pulmonary fibrosis. Org Biomol Chem 14:5992-6009.

Busk M, Pytela R, and Sheppard D (1992) Characterization of the integrin alpha v beta 6 as a fibronectin-binding protein. J Biol Chem 267:5790-5796

Carron CP, Meyer DM, Pegg JA, Engleman VW, Nickols MA, Settle SL, Westlin WF, Ruminski PG, and Nickols GA (1998) A peptidomimetic antagonist of the integrin alpha(v)beta3 inhibits Leydig cell tumor growth and the development of hypercalcemia of malignancy. Cancer Res 58:1930-1935.

Dozynkiewicz MA, Jamieson NB, Macpherson I, Grindlay J, van den Berghe PV, von Thun A, Morton JP, Gourley C, Timpson P, Nixon C, et al. (2012) Rab25 and CLIC3 collaborate to promote integrin recycling from late endosomes/lysosomes and drive cancer progression. Dev Cell 22:131-145. 
Dunmore BJ, Drake KM, Upton PD, Toshner MR, Aldred MA, and Morrell NW (2013) The lysosomal inhibitor, chloroquine, increases cell surface BMPR-II levels and restores BMP9 signalling in endothelial cells harbouring BMPR-II mutations. Hum Mol Genet 22:3667-3679.

Goodwin A and Jenkins G (2009) Role of integrin-mediated TGFbeta activation in the pathogenesis of pulmonary fibrosis. Biochem Soc Trans 37:849-854.

Grygielko ET, Martin WM, Tweed C, Thornton P, Harling J, Brooks DP, and Laping NJ (2005) Inhibition of gene markers of fibrosis with a novel inhibitor of transforming growth factor-beta type I receptor kinase in puromycin-induced nephritis. J Pharmacol Exp Ther 313:943-951.

Harling JD, Deakin AM, Campos S, Grimley R, Chaudry L, Nye C, Polyakova O, Bessant CM, Barton N, Somers D, et al. (2013) Discovery of novel irreversible inhibitors of interleukin (IL)-2-inducible tyrosine kinase (Itk) by targeting cysteine 442 in the ATP pocket. J Biol Chem 288:28195-28206.

Hatley RJD, Macdonald SJF, Slack RJ, Le J, Ludbrook SB, and Lukey PT (2018) An $\alpha$ v-RGD integrin inhibitor toolbox: drug discovery insight, challenges and opportunities. Angew Chem Int Ed Engl 57:3298-3321.

Hausner SH, Abbey CK, Bold RJ, Gagnon MK, Marik J, Marshall JF, Stanecki CE, and Sutcliffe JL (2009) Targeted in vivo imaging of integrin alphavbeta6 with an improved radiotracer and its relevance in a pancreatic tumor model. Cancer Res 69:5843-5850.

Horan GS, Wood S, Ona V, Li DJ, Lukashev ME, Weinreb PH, Simon KJ, Hahm K, Allaire NE, Rinaldi NJ, et al. (2008) Partial inhibition of integrin alpha(v)beta6 prevents pulmonary fibrosis without exacerbating inflammation. Am $J$ Respir Crit Care Med 177:56-65.

Hulme EC and Trevethick MA (2010) Ligand binding assays at equilibrium: validation and interpretation. Br J Pharmacol 161:1219-1237.

Hynes RO (1987) Integrins: a family of cell surface receptors. Cell 48:549-554.

Hynes RO (2002) Integrins: bidirectional, allosteric signaling machines. Cell 110 $673-687$.

Kelly E, Bailey CP, and Henderson G (2008) Agonist-selective mechanisms of GPCR desensitization. Br J Pharmacol 153 (Suppl 1):S379-S388.

Livak KJ and Schmittgen TD (2001) Analysis of relative gene expression data using real-time quantitative PCR and the 2(-Delta Delta C(T)) Method. Methods 25: 402-408.

Long MJ, Gollapalli DR, and Hedstrom L (2012) Inhibitor mediated protein degradation. Chem Biol 19:629-637.

Maden CH, Fairman D, Chalker M, Costa MJ, Fahy WA, Garman N, Lukey PT, Mant T, Parry S, Simpson JK, et al. (2018) Safety, tolerability and pharmacokinetics of GSK3008348, a novel integrin $\alpha \mathrm{v} \beta 6$ inhibitor, in healthy participants. Eur J Clin Pharmacol 74:701-709.

Margadant C and Sonnenberg A (2010) Integrin-TGF-beta crosstalk in fibrosis, cancer and wound healing. EMBO Rep 11:97-105.

Munger JS, Huang X, Kawakatsu H, Griffiths MJ, Dalton SL, Wu J, Pittet JF, Kaminski N, Garat C, Matthay MA, et al. (1999) The integrin alpha v beta 6 binds and activates latent TGF beta 1: a mechanism for regulating pulmonary inflammation and fibrosis. Cell 96:319-328.

Ramsay AG, Keppler MD, Jazayeri M, Thomas GJ, Parsons M, Violette S, Weinreb P Hart IR, and Marshall JF (2007) HS1-associated protein X-1 regulates carcinoma cell migration and invasion via clathrin-mediated endocytosis of integrin alphavbeta6. Cancer Res 67:5275-5284.

Rowedder JE, Ludbrook SB, and Slack RJ (2017) Determining the true selectivity profile of $\alpha v$ integrin ligands using radioligand binding: applying an old solution to a new problem. SLAS Discov 22:962-973.

Ruoslahti E (1996) RGD and other recognition sequences for integrins. Annu Rev Cell Dev Biol 12:697-715.

Saha A, Ellison D, Thomas GJ, Vallath S, Mather SJ, Hart IR, and Marshall JF (2010) High-resolution in vivo imaging of breast cancer by targeting the proinvasive integrin alphavbeta6. J Pathol 222:52-63.

Slack RJ, Hafeji M, Rogers R, Ludbrook SB, Marshall JF, Flint DJ, Pyne S, and Denyer JC (2016) Pharmacological characterization of the $\alpha \mathrm{v} \beta 6$ integrin binding and internalization kinetics of the foot-and-mouth disease virus derived peptide A20FMDV2. Pharmacology 97:114-125.

Solomon VR and Lee H (2009) Chloroquine and its analogs: a new promise of an old drug for effective and safe cancer therapies. Eur J Pharmacol 625:220-233.

Tatler AL and Jenkins G (2012) TGF- $\beta$ activation and lung fibrosis. Proc Am Thorac Soc 9:130-136.

Wang A, Yokosaki Y, Ferrando R, Balmes J, and Sheppard D (1996) Differential regulation of airway epithelial integrins by growth factors. Am J Respir Cell Mol Biol 15:664-672.

Wang J, Wu J, Hong J, Chen R, Xu K, Niu W, Peng C, Liu E, Wang J, Liu S, et al. (2011) PKC promotes the migration of colon cancer cells by regulating the internalization and recycling of integrin $\alpha \mathrm{v} \beta 6$. Cancer Lett 311:38-47.

Weinreb PH, Simon KJ, Rayhorn P, Yang WJ, Leone DR, Dolinski BM, Pearse BR, Yokota Y, Kawakatsu H, Atakilit A, et al. (2004) Function-blocking integrin alphavbeta6 monoclonal antibodies: distinct ligand-mimetic and nonligandmimetic classes. J Biol Chem 279:17875-17887.

Xu MY, Porte J, Knox AJ, Weinreb PH, Maher TM, Violette SM, McAnulty RJ, Sheppard D, and Jenkins G (2009) Lysophosphatidic acid induces alphavbeta6 integrin-mediated TGF-beta activation via the LPA2 receptor and the small G protein G alpha(q). Am J Pathol 174:1264-1279.

Zambruno G, Marchisio PC, Marconi A, Vaschieri C, Melchiori A, Giannetti A, and De Luca M (1995) Transforming growth factor-beta 1 modulates beta 1 and beta 5 integrin receptors and induces the de novo expression of the alpha $\mathrm{v}$ beta 6 heterodimer in normal human keratinocytes: implications for wound healing. J Cell Biol 129:853-865.

Address correspondence to: James A. Roper, Fibrosis DPU, Respiratory TAU, GlaxoSmithKline, Gunnels Wood Rd., Stevenage, Hertfordshire, UK SG1 2NY. E-mail: James.X.Roper@gsk.com 